\title{
The tracking of dietary intakes of children and adolescents in Sweden over six years: the European Youth Heart Study Emma Patterson*1,2, Julia Wärnberg ${ }^{1,3}$, John Kearney ${ }^{2}$ and Michael Sjöström ${ }^{1}$
}

\begin{abstract}
Address: ${ }^{1}$ Unit for Preventive Nutrition, Department of Biosciences and Nutrition, Karolinska Institutet, 14157 Huddinge, Sweden, ${ }^{2}$ School of Biological Sciences, Dublin Institute of Technology, Dublin 2, Ireland and ${ }^{3}$ Department of Preventive Medicine and Public Health, University of Navarra, 31080 Pamplona, Spain
\end{abstract}

Email: Emma Patterson* - emma.patterson@ki.se; Julia Wärnberg - julia.warnberg@ki.se; John Kearney - john.kearney@dit.ie; Michael Sjöström - michael.sjostrom@ki.se

* Corresponding author

Published: II December 2009

International Journal of Behavioral Nutrition and Physical Activity 2009, 6:91 doi:10.1186/1479-5868-6-91

This article is available from: http://www.ijbnpa.org/content/6/I/9I

(c) 2009 Patterson et al; licensee BioMed Central Ltd.

This is an Open Access article distributed under the terms of the Creative Commons Attribution License (http://creativecommons.org/licenses/by/2.0), which permits unrestricted use, distribution, and reproduction in any medium, provided the original work is properly cited.
Received: 15 May 2009

Accepted: II December 2009

\begin{abstract}
Background: The stability of dietary habits through various life-stages is not well understood. A better understanding of the tracking of diet over time could have implications for health promotion as well as for the planning of nutritional epidemiology studies. We examined the stability of dietary intakes of children and adolescents over six years.
\end{abstract}

Methods: As part of the European Youth Heart Study, in 1998-9, a 24-h dietary recall was performed on over one thousand 9- and I5-year-olds in Sweden. In 2004-5, 40\% returned to the follow-up study. These 452 subjects (273 15- and 17921 -year-olds) were assigned to age- and gender-specific tertiles of intakes of food groups, energy, selected nutrients and energy density (low, mid and high) at each time point. The agreement between the classification of subjects into tertiles at both time points was examined using Cohen's weighted $\kappa$ and other stability coefficients. We included a dropout analysis and considered the effect that energy mis-reporting might have on our results.

Results: Fair tracking was seen between childhood and adolescence for the milk, fil and yoghurt food group $(\kappa=0.30)$, and between adolescence and young adulthood for fruit $(\kappa=0.24)$. Slight tracking was observed for most other food groups and fair to slight tracking for all nutrients studied. Only membership of the high milk, fil and yoghurt tertile could be predicted from membership at baseline, in children. Excluding potential energy mis-reporters did not affect the results.

Conclusions: Despite the long time between data collections, and the method of dietary data collection used, evidence for slight tracking was observed for most food groups and nutrients over these six years.

\section{Background}

Many established biological cardiovascular disease risk factors are known to track, or remain relatively consistent, with age; for example, high cholesterol, low physical fit- ness and high body mass index $[1,2]$. Despite the recognised association between diet and cardiovascular disease risk factors, less is known about the conservation of dietary habits in children and adolescents [3-6]. Assumptions 
about the formation and stability of dietary habits during childhood and adolescence are often used as the basis for costly and labour-intense behavioural interventions [7]. The evidence for this stability in relation to dietary habits in young people is limited, and most studies report only poor to moderate tracking.

Tracking is defined as "stability over time" [8]. It can be thought of as the position a person holds relative to his or her peers at one time point, to that held at another time point. A better understanding of this phenomenon is important for several reasons. For the promotion of healthy eating it is necessary to know if there are certain life-stages at which young people are more amenable to messages and when changes effected may persist for a long time. For the planning of longitudinal epidemiological studies it is important to know how often dietary assessments should be made, as if, for example, periods of stability are identified, fewer assessments may be necessary [9].

One of the barriers to studying tracking is that cohort or long-term studies are required, and these tend to be less common than cross-sectional studies. The European Youth Heart Study [10] was designed to study the development and progression of cardiovascular risk factors in otherwise healthy children and adolescents as they transition to adolescence and young adulthood, respectively. It therefore provided a valuable opportunity to examine dietary habits and their behaviour over time. We examined the intakes of food groups, energy and selected nutrients in a sample of children and adolescents, followed-up after six years, and here we report the tracking of those intakes.

\section{Methods \\ Study design}

Data collection for the Swedish part of the European Youth Heart Study (EYHS) was conducted in 1998-99 (EYHS I) and 2004-5 (EYHS II). Over two thousand ( $\mathrm{n}=$ 2313 ) children (from grade 3 , mean age 9 years) and adolescents (grade 9, mean age 15 years) were sampled from classes selected from 42 schools in southern Stockholm and Örebro. Of these, 1137 students consented to participate in EYHS I, and six years later 459 agreed to take part in EYHS II. Permission was obtained from the local ethical committees (Huddinge University Hospital, permit no. 474/98; Örebro City Council, no. 690/98). Data collection was performed in schools in EYHS I, and on site at Karolinska Institutet (Stockholm) and Örebro University for EYHS II. Written consent was provided by a parent or legal guardian and verbal consent was provided by all 9and 15-year-old subjects; written consent was provided by the 21-year-old subjects in EYHS II. A more detailed description of the study and the sampling procedure [11] has been published. Complete dietary data was available at both time points for 452 subjects: 273 younger subjects (9 years old, followed up when 15), and 179 older subjects (15 years old, followed up when 21).

\section{Dropout analysis}

Subjects from EYHS I who participated in EYHS II ("participants") did not differ from those who did not ("dropouts") in relation to physical activity, physical fitness or anthropometric indices at EYHS I [12]. A separate dropout analysis focusing on dietary intake found no major discrepancies between the diets of participants and dropouts (Patterson et al, unpublished results). Significant differences were seen in the percent consumers of one food group (out of 19) and in one diet-related frequency question (of 11), after Bonferroni correction for multiple comparisons. Percent energy from carbohydrate was marginally higher in the participants than dropouts $(\mathrm{p}=$ 0.04) but neither other macronutrients, energy intake, energy density nor inadequate energy reporting differed between the two groups $(\mathrm{p}>0.05)$.

\section{Dietary data collection}

The subjects completed a single 24 -h recall, conducted by a trained interviewer. In EYHS I, the 9-year-old children kept a 1-d qualitative food diary with the assistance of their parents on the day before the interview, to aid as a prompt in case of difficulties with the recall. Otherwise, the protocol remained unchanged between EYHS I and II. A food atlas with pictures of common foods in various portion sizes was available during the interview, along with standard household units to help estimate quantities accurately. Data from the recall was analysed using the dietary analysis software Stor MATs (Rudans Lättdata, Västerås, Sweden); version 4.02 based on the Swedish Food Administration's http://www.slv.se nutritional database 99.1 (EYHS I), and version 4.06 with database 02.1 (EYHS II). Each food consumed was allocated to a food group based on nutritional or dietary similarities and intakes are presented at food group level. Most food groups are self-explanatory, with some clarifications: the "milk, fil, yoghurt" group includes fil, a soured-milk product similar to yoghurt, common in Nordic countries; "sweetened drinks" includes sugar-sweetened carbonated or cordial-based drinks; "fruit juices" refers to concentrated or fresh juices; the "other sweet foods" group includes desserts, ice-cream, sweet soups, jams and added sugar; "cereals" refer to breakfast cereals (including porridge); fried potatoes are included in the "chips, crisps" group. Someone who reported eating any amount of a food group was considered a consumer of that food group. Energy density was calculated as the total energy from food (kJ) consumed divided by the total weight of the food (g). Food was defined as solid food and liquids consumed as food (e.g. soups, yoghurt). All beverages, both energy-containing and non-energy-containing were 
excluded from this calculation. Energy density was used as a marker of overall dietary quality [13].

Age- and gender-specific tertiles of food group intakes, energy, selected nutrients and dietary energy density were calculated at each time point and subjects were deemed to have low, medium or high intakes, relative to their peers.

\section{Energy reporting}

In order to identify subjects who may have mis-reported dietary intakes to a significant degree, we used the method proposed by Goldberg and colleagues [14] and calculated a $95 \%$ confidence interval around predicted intakes required for weight maintenance. Subjects with energy intakes above or below these upper and lower values were deemed "inadequate" reporters, and those within the cutoffs, "adequate" reporters. Physical activity level values and other data required for the calculation of Goldberg cut-offs were taken from Black [15]. In our study, 9-yearolds were defined as adequate reporters if they had a ratio of reported energy to predicted energy of between 0.97 and 2.91 (girls) or between 0.98 and 3.08 (boys); 15 -yearolds had cut-offs of 0.98 and 2.98 (girls), and 1.03 and 3.06 (boys); 21-year-olds had cut-offs of 0.93 and 3.05 (girls) and 1.00 and 3.41 (boys). As this method makes many assumptions, and is particularly insensitive at the individual level when the duration of dietary record is short [16], we did not exclude the "inadequate" reporters from the main analysis. Instead, we present the numbers mis-reporting, and we re-ran all analysis with "adequate" reporters only and identified any significant differences from the main analysis. Basal metabolic rate was estimated from equations developed by Schofield [17].

\section{Other data}

Height and weight were measured according to standardised procedures. Overweight status was determined by comparing a subject's body mass index (BMI, $\mathrm{kg} / \mathrm{m} 2$ ) to cut-offs established by Cole et al. [18] for children and adolescents. For the 21-year-old subjects, BMI was compared to the WHO adult reference range [19].

\section{Statistical analysis}

The agreement between tertile membership at EYHS I and tertile membership at EYHS II was estimated in three ways, each assessing a specific aspect of tracking behaviour [8].

1) The proportion of stability is the crudest measure and is simply the proportion of subjects who remained in the same tertile at both time points divided by the total number of subjects. If chance alone determined the tertile at time II, one third would be expected to be placed in the same tertile; a value $>33$ therefore suggests that subjects do not stay in the same tertile completely by chance.

2) For overall tracking, Cohen's weighted $\kappa$ was used [20]. This is a measure of the level of agreement between tertile membership at time I and time II, with membership of the same tertile seen as perfect agreement, but with some weighting given to membership of an adjacent tertile and none to an extreme tertile; e.g. movement from low to moderate is weighted more heavily than movement from low to high. Cohen's weighted $\kappa$ calculates a value usually between zero and one, where one indicates perfect agreement. The interpretation of a tracking coefficient is subjective, but certain scales have been adopted, for example that of Landis and Koch [21], which judges values of 0.01 to 0.20 as indicative of "slight" agreement; 0.21 to 0.40 as "fair"; 0.41 to 0.60 as "moderate"; 0.61 to 0.80 as "substantial" and 0.81 to 1.00 as "almost perfect" agreement.

3) A predictive value for remaining in the highest tertile was also calculated. This is the proportion of subjects in the highest tertile at time I who remained in the highest tertile at time II, divided by those in the highest tertile at time I who had moved to other tertiles at time II. A value $>1$ suggests more subjects stayed than moved.

All statistical analysis was performed using SPSS for Windows, v. 17 (Chicago, USA). Cohen's weighted $\kappa$ is not available in the standard SPSS package, but command syntax is available by searching the SPSS.com "Knowledgebase" [22]. Data for imputation into the syntax was generated from cross-tabulation. For food groups with high levels of non-consumers, occasionally tertiles were of unequal size, and sometimes only two "tertiles" could be created. SPSS assigns all non-consumers automatically to tertile 1 , and the upper cut-off is still made as close to the $66^{\text {th }}$ percentile as possible, which may result in tertiles 1 , 2 and 3 being of different sizes. For food groups with very high non-consumption levels, the $33^{\text {rd }}$ and $66^{\text {th }}$ percentile of intake might both be zero; all non-consumers are assigned to "tertile" 1 and the remaining to a second "tertile". If the same numbers of "tertiles" are not available at both time points, predictive values and Cohen's $\kappa$ cannot be calculated. This was an issue for a total of four food groups. Because of the skewed data, median, $25^{\text {th }}$ and $75^{\text {th }}$ percentile intakes are presented for food groups and nutrients. Data on food group intakes is presented for consumers of those food groups only. The proportion of subjects consuming a food group at time I and time II was compared using a non-parametric paired-sample test $(\mathrm{McNe}$ mar test). To test for the effect of the predictors age and gender on the outcome of stability, a logistic regression was performed, including an age by gender interaction 
effect. The level of statistical significance was set at $\mathrm{p}<$ 0.05 .

\section{Results \\ Participants}

Subject characteristics are presented in Table 1. Approximately $40 \%$ of subjects returned to EYHS II. As previously described in the EYHS dropout analysis, the older group in EYHS I were less likely than the younger group to return, and boys were less likely to return than girls. At time I and time II, approximately $85 \%$ of the sample were of normal weight. In EYHS I, 94\% of the sample reported an adequate energy intake, and in EYHS II this was 79\%; the percentage adequately reporting at both time points is presented in the table. Inadequate reporting here refers to both under- and over-reporting, but over-reporting was rare (data not shown).

\section{Food groups and nutrients}

The most commonly consumed food groups (Table 2) were bread; milk, fil and yoghurt; meat and meat dishes; vegetables; and pasta, rice and potatoes - these food groups were consumed by more than $66 \%$ of both age groups at both time points. Relative to the percentage at time I, from 9 to 15 years the percentage of consumers of cakes and biscuits; sweets and chocolate and "other sweet things" decreased most, while poultry and poultry dishes; chips and crisps, and cheese increased most. From 15 to 21 years, the numbers consuming sweets and chocolate; spreads and oils, and sweetened drinks decreased most, while chips and crisps, and poultry and poultry dishes increased the most. Intakes of energy, selected nutrients and dietary energy density are presented in Table 3.

\section{Tracking coefficients}

The tracking coefficients for food groups, energy, selected nutrients and energy density are presented in Table 4 . The highest proportion of stability seen was between childhood and adolescence for poultry and poultry dishes; chips and crisps; pizza, pies and pancakes, although these values are likely to be inflated because of the high proportion of non-consumers at both time points. The highest stability values in the older age group were seen for poultry and poultry dishes; pizza, pies and pancakes group, and cakes and biscuits. Again, the low consumption rates of the first two groups should be taken into consideration. Stability did not generally differ by gender, with the exceptions of fruit (where boys were more likely to be stable than girls); cakes and biscuits in the younger age group (girls were more likely to be stable), and chips and crisps in the older age group (boys were more likely to be stable).

In the younger subjects, Cohen's $\kappa$ coefficients of largest magnitude were seen for milk, fil, yoghurt; cheese; cereals, and vegetables. In the older age group, fruit; vegetables; sweetened drinks; pasta, rice and potatoes, and sweets and chocolate showed the most agreement. The predictive value of membership of the highest tertile at time II based on membership at time I was highest for milk, fil and yoghurt; cheese, and cereals (but only milk, fil and yoghurt had a value $>1.0$ ) in the younger group. Fruit; vegetables; sweets and chocolate; sweetened drinks, and cereals had the highest predictive values in the older age group (no value was higher than 0.69 ). For nutrients, stability was highest for calcium from 9 years to 15 years. Cohen's $\kappa$ was highest for calcium and sucrose $(>0.11)$, and the predictive values were highest for calcium and saturated fat. Stability in the older age group was highest for fibre, vitamin $\mathrm{C}$ and protein. Cohen's $\kappa$ was highest for fibre, vitamin $\mathrm{C}$ and protein $(>0.16)$. The predictive values were also highest for fibre, vitamin $\mathrm{C}$, sucrose and folic acid. Energy density, a marker of overall dietary quality, had low stability and slight $\kappa$ values in both age groups.

In summary, in the younger age group, 14 out of the 17 food groups examined had stability values $>33$. The milk,

Table I: Participant characteristics

\begin{tabular}{|c|c|c|c|c|c|c|c|c|c|c|c|c|}
\hline & \multirow{4}{*}{$\begin{array}{c}\text { Sample } \\
\text { n (\%) }\end{array}$} & \multicolumn{5}{|c|}{ EYHS I } & \multicolumn{5}{|c|}{ EYHS II } & \multirow{4}{*}{$\begin{array}{c}\text { Adequate reporting } \\
\%\end{array}$} \\
\hline & & \multirow{3}{*}{$\begin{array}{l}\text { Age }^{a} \\
\text { years }\end{array}$} & & & \multicolumn{2}{|c|}{ Weight status } & \multirow{3}{*}{$\begin{array}{l}\text { Age }^{a} \\
\text { years }\end{array}$} & \multicolumn{4}{|c|}{ Weight status } & \\
\hline & & & \multicolumn{2}{|c|}{ BMIb } & \multirow{2}{*}{$\begin{array}{c}\text { normal } \\
\%\end{array}$} & \multirow{2}{*}{$\begin{array}{c}\text { obese } \\
\%\end{array}$} & & \multicolumn{2}{|c|}{ BMIb } & \multirow{2}{*}{$\begin{array}{c}\text { normal } \\
\%\end{array}$} & \multirow{2}{*}{$\begin{array}{c}\text { obese } \\
\%\end{array}$} & \\
\hline & & & $\mathrm{kg} / \mathrm{m}^{2}$ & SD & & & & $\mathrm{kg} / \mathrm{m}^{2}$ & SD & & & \\
\hline Younger girls & $149(33)$ & 9.5 & 17.2 & 2.3 & 85.8 & 1.4 & 15.5 & 20.9 & 2.6 & 89.3 & 1.3 & 79.7 \\
\hline Younger boys & $124(27)$ & 9.5 & 17.2 & 2.4 & 85.4 & 2.4 & 15.5 & 20.5 & 2.9 & 84.6 & 0.8 & 71.3 \\
\hline Older girls & $110(24)$ & 15.5 & 21.1 & 2.5 & 89.9 & 0.9 & $2 I^{d}$ & 22.4 & 3.3 & 84.4 & 4.6 & 70.4 \\
\hline Older boys & $69(15)$ & 15.5 & 20.7 & 2.9 & 89.9 & 1.4 & $21^{d}$ & 23.3 & 3.6 & 78.3 & 5.8 & 81.2 \\
\hline
\end{tabular}

a Mean decimal age

b Mean BMI plus standard deviation (SD)

c Reported adequate energy intake at both time points. See Methods section for definition

d Exact decimal age not available 
Table 2: Consumers (\%) and intakes of food group consumers (g)

\begin{tabular}{|c|c|c|c|c|c|c|c|c|c|}
\hline \multirow{3}{*}{ Younger group } & \multicolumn{4}{|c|}{ EYHS I } & \multicolumn{5}{|c|}{ EYHS II } \\
\hline & \multicolumn{7}{|c|}{ Percentiles } & \multicolumn{2}{|c|}{ Percentiles } \\
\hline & $\%$ & Median & $25^{\text {th }}$ & $7^{\text {th }}$ & $\%$ & & Median & $25^{\text {th }}$ & $7^{\text {th }}$ \\
\hline Bread & 94.5 & 86 & 50 & 140 & 87.5 & $\mathrm{a}$ & 100 & 59 & 165 \\
\hline Milk, fil, yoghurt & 97.4 & 588 & 364 & 824 & 92.3 & a & 552 & 352 & 839 \\
\hline Cheese & 40.7 & 35 & 20 & 60 & 51.6 & a & 40 & 23 & 80 \\
\hline Vegetables & 79.1 & 58 & 30 & 94 & 70.3 & $\mathrm{a}$ & 65 & 36 & 120 \\
\hline Fruit & 60.4 & 150 & 105 & 253 & 56.4 & & 200 & 105 & 300 \\
\hline Fruit juice & 34.8 & 206 & 150 & 382 & 35.9 & & 250 & 200 & 500 \\
\hline Pasta, rice, potatoes & 81.7 & 225 & 150 & 310 & 75.8 & & 210 & 130 & 325 \\
\hline Cereals & 44.0 & 41 & 20 & 200 & 46.5 & & 60 & 35 & 150 \\
\hline Pizza, pies, pancakes & 24.2 & 205 & 140 & 265 & 18.7 & & 250 & 170 & 350 \\
\hline Meat, meat dishes & 83.9 & 150 & 70 & 230 & 82.4 & & 200 & 95 & 320 \\
\hline Poultry, poultry dishes & 11.7 & 100 & 80 & 120 & 18.3 & a & 95 & 60 & 200 \\
\hline Spreads and oils & 88.3 & 15 & 9 & 25 & 79.5 & a & 11 & 6 & 20 \\
\hline Sweets, chocolate & 64.8 & 16 & 8 & 34 & 39.6 & a & 40 & 20 & 89 \\
\hline Cakes, biscuits & 49.8 & 51 & 30 & 94 & 28.6 & a & 56 & 30 & 100 \\
\hline Other sweet foods & 68.9 & 65 & 20 & 175 & 49.8 & a & 60 & 15 & 140 \\
\hline Sweetened drinks & 49.1 & 252 & 200 & 501 & 46.9 & & 400 & 250 & 638 \\
\hline Chips, crisps & 16.1 & 99 & 16 & 171 & 22.7 & & 102 & 48 & 150 \\
\hline \multirow[t]{2}{*}{ Older group } & \multicolumn{7}{|c|}{ Percentiles } & \multicolumn{2}{|c|}{ Percentiles } \\
\hline & $\%$ & Median & $25^{\text {th }}$ & $7^{\text {th }}$ & $\%$ & & Median & $25^{\text {th }}$ & $75^{\text {th }}$ \\
\hline Bread & 97.8 & 120 & 75 & 178 & 89.4 & a & 105 & 60 & 170 \\
\hline Milk, fil, yoghurt & 94.4 & 600 & 412 & 931 & 83.2 & a & 380 & 200 & 600 \\
\hline Cheese & 61.5 & 40 & 21 & 73 & 64.8 & & 48 & 25 & 80 \\
\hline Vegetables & 75.4 & 100 & 50 & 170 & 77.7 & & 105 & 55 & 205 \\
\hline Fruit & 52.5 & 190 & 105 & 293 & 53.6 & & 200 & 109 & 366 \\
\hline Fruit juice & 36.9 & 344 & 206 & 415 & 29.6 & & 252 & 200 & 435 \\
\hline Pasta, rice, potatoes & 70.4 & 225 & 150 & 301 & 66.5 & & 160 & 125 & 235 \\
\hline Cereals & 43.0 & 45 & 20 & 175 & 44.7 & & 59 & 30 & 200 \\
\hline Pizza, pies, pancakes & 17.3 & 170 & 118 & 280 & 15.1 & & 250 & 200 & 350 \\
\hline Meat, meat dishes & 82.7 & 150 & 74 & 214 & 72.6 & a & 180 & 86 & 310 \\
\hline Poultry, poultry dishes & 8.4 & 140 & 80 & 200 & 16.2 & a & 100 & 60 & 180 \\
\hline Spreads and oils & 87.2 & 15 & 9 & 24 & 65.9 & a & 12 & 6 & 20 \\
\hline Sweets, chocolate & 78.8 & 35 & 12 & 87 & 35.2 & a & 65 & 25 & 100 \\
\hline Cakes, biscuits & 38.0 & 60 & 30 & 106 & 38.5 & & 60 & 38 & 125 \\
\hline Other sweet foods & 58.7 & 51 & 17 & 153 & 48.0 & & 50 & 14 & 150 \\
\hline Sweetened drinks & 54.7 & 412 & 267 & 669 & 43.0 & a & 375 & 250 & 600 \\
\hline Chips, crisps & 27.4 & 100 & 33 & 161 & 34.1 & & 75 & 35 & 150 \\
\hline
\end{tabular}

Intakes are for consumers only

Consumers: percent of subjects consuming food group

a Significantly different from EYHS I (McNemar test), $\mathrm{p}<0.05$

fil, and yoghurt group showed fair tracking, and seven others showed slight tracking. Milk, fil, yoghurt also had a positive predictive value for the highest tertile. All nutrients had stability values $>33$, and all showed slight tracking. In the older age group, 14 of the 17 food groups had stability values $>33$; fair tracking was seen for fruit intake and slight tracking for a further ten food groups. Again, all nutrients had stability values $>33$, fibre showed fair tracking and all others showed slight tracking.

\section{Exclusion of inadequate energy reporters}

Re-analysis of the data with inadequate reporters excluded resulted in some small changes to percent consumers of food groups and intakes (data not shown), but the tracking statistics did not differ substantially. One additional food group in the older subjects showed fair tracking (vegetables), and fibre, which had fair tracking, became slight. In the younger age group, folic acid showed no tracking, instead of slight. Stability coefficients were similar. The positive predictive value for milk, fil, yoghurt in the 
Table 3: Intakes of nutrients

\begin{tabular}{|c|c|c|c|c|c|c|}
\hline \multirow{3}{*}{ Younger group } & \multicolumn{3}{|c|}{ EYHS I } & \multicolumn{3}{|c|}{ EYHS II } \\
\hline & \multicolumn{3}{|c|}{ Percentiles } & \multicolumn{3}{|c|}{ Percentiles } \\
\hline & Median & $25^{\text {th }}$ & $7^{\text {th }}$ & Median & $25^{\text {th }}$ & $75^{\text {th }}$ \\
\hline Energy (MJ) & 8.4 & 7.0 & 9.9 & 9.6 & 7.0 & 12.1 \\
\hline Energy $(\mathrm{MJ} / \mathrm{kg})^{\mathrm{a}}$ & 0.26 & 0.21 & 0.31 & 0.16 & 0.12 & 0.21 \\
\hline Protein (\% E) & 15.2 & 13.1 & 17.2 & 16.2 & 13.3 & 18.5 \\
\hline Fat $(\% \mathrm{E})$ & 32.1 & 28.3 & 36.4 & 31.3 & 26.8 & 37.2 \\
\hline Saturated fat $(\% \mathrm{E})$ & 14.6 & 12.7 & 16.4 & 14.1 & 11.8 & 17.1 \\
\hline Carbohydrates (\% E) & 52.0 & 47.6 & 56.5 & 51.0 & 46.0 & 56.4 \\
\hline Sucrose (\% E) & 10.1 & 6.7 & 14.0 & 9.8 & 6.1 & 13.7 \\
\hline Fibre $(g)$ & 14.0 & 10.6 & 17.4 & 17.2 & 11.6 & 23.8 \\
\hline Vitamin C (mg) & 73.4 & 37.3 & 123 & 69.8 & 32.5 & 148 \\
\hline Folate $(\mu \mathrm{g})$ & 194 & 156 & 240 & 236 & 169 & 316 \\
\hline Iron (mg) & 8.4 & 6.6 & 11.0 & 11.1 & 7.3 & 15.9 \\
\hline Calcium (mg) & 1113 & 838 & 1560 & 1198 & 826 & 1652 \\
\hline Energy density $(\mathrm{kJ} / \mathrm{g})$ & 6.5 & 5.6 & 7.6 & 6.9 & 5.9 & 8.3 \\
\hline \multirow[t]{2}{*}{ Older group } & \multicolumn{4}{|c|}{ Percentiles } & \multicolumn{2}{|c|}{ Percentiles } \\
\hline & Median & $25^{\text {th }}$ & $7^{\text {th }}$ & Median & $25^{\text {th }}$ & $75^{\text {th }}$ \\
\hline Energy (MJ) & 10.2 & 7.5 & 12.1 & 9.3 & 6.7 & 12.1 \\
\hline Energy $(\mathrm{MJ} / \mathrm{kg})^{\mathrm{a}}$ & 0.17 & 0.13 & 0.20 & 0.14 & 0.10 & 0.18 \\
\hline Protein (\% E) & 14.4 & 11.9 & 17.3 & 14.9 & 12.8 & 17.9 \\
\hline Fat $(\% \mathrm{E})$ & 31.2 & 26.4 & 35.2 & 32.6 & 26.7 & 38.4 \\
\hline Saturated fat (\% E) & 14.5 & 11.7 & 16.7 & 13.2 & 10.3 & 16.4 \\
\hline Carbohydrates (\% E) & 54.4 & 48.7 & 58.4 & 50.4 & 44.2 & 56.0 \\
\hline Sucrose (\% E) & 11.7 & 7.6 & 16.0 & 10.1 & 5.8 & 13.4 \\
\hline Fibre $(\mathrm{g})$ & 16.9 & 11.8 & 22.0 & 19.0 & 13.3 & 24.4 \\
\hline Vitamin C (mg) & 87.9 & 37.5 & 192 & 74.2 & 34.4 & 134 \\
\hline Folate $(\mu g)$ & 235 & 177 & 311 & 239 & 180 & 339 \\
\hline Iron (mg) & 10.8 & 7.9 & 13.8 & 10.9 & 7.4 & 15.7 \\
\hline Calcium (mg) & 1312 & 935 & 1777 & 1041 & 640 & $|46|$ \\
\hline Energy density $(\mathrm{k} / \mathrm{g})$ & 6.5 & 5.6 & 7.6 & 6.9 & 5.9 & 8.3 \\
\hline
\end{tabular}

$\% E$ is a percentage of total energy

${ }^{a}$ per $\mathrm{kg}$ body weight

younger group disappeared (became 0.94), while vegetables in the older group became borderline (1.00).

\section{Discussion}

Despite using a dietary assessment method which has known limitations for measuring at the individual level, and over a relatively long time period, we found evidence of slight to fair tracking for many of the food groups and all of the nutrients studied, indicating some stability of intakes at individual level.

\section{Interpreting tracking coefficients}

Interpreting tracking coefficients is hampered by the many ways in which they can be calculated, and a lack of consensus on how to interpret them [8]. The time period over which they are measured is another important factor. A high tracking coefficient over a short time may be just evidence of the reliability of the method used, whereas more modest coefficients over many years, as we generally found, could be stronger evidence of tracking [23]. In cases of food groups where the level of non-consumers is high - a problem when only one day of intake is available - the stability coefficient can be artificially inflated. Another factor that influences the interpretation is the measurement error of the methods used. A single 24-h recall does not reflect usual dietary intake well at the individual level. However, the expected effect of using a method with a large measurement error is to attenuate statistical associations. Therefore, the finding of tracking is noteworthy. In addition to these factors, we assessed tracking across very different age groups. Childhood, adolescence and young adulthood are three distinct lifestages, and the environmental influences on diet vary considerably at each age $[5,24]$. Children are restricted by 
Table 4: Tracking values

\begin{tabular}{|c|c|c|c|c|c|c|}
\hline & \multicolumn{3}{|c|}{ Younger group (EYHS I to EYHS II) } & \multicolumn{3}{|c|}{ Older group (EYHS I to EYHS II) } \\
\hline & Stability ${ }^{a}$ & Cohen's $\kappa^{b}$ & Predictive value $^{c}$ & Stability ${ }^{a}$ & Cohen's $\kappa^{b}$ & Predictive value $^{c}$ \\
\hline \multicolumn{7}{|l|}{ Food groups } \\
\hline Bread & 0.36 & 0.06 & 0.76 & 0.36 & 0.06 & 0.50 \\
\hline Milk, fil, yoghurt & 0.49 & 0.30 & 1.17 & 0.35 & 0.06 & 0.58 \\
\hline Cheese & 0.49 & 0.16 & 0.86 & 0.29 & $<0$ & 0.45 \\
\hline Vegetables & 0.38 & 0.11 & 0.55 & 0.40 & 0.17 & 0.79 \\
\hline Fruit & 0.40 & 0.10 & 0.76 & 0.49 & 0.23 & 0.82 \\
\hline Fruit juice & 0.14 & $<0$ & 0.45 & 0.16 & $\mathrm{n} / \mathrm{a}$ & 0.67 \\
\hline Pasta, rice, potatoes & 0.37 & 0.06 & 0.55 & 0.44 & 0.14 & 0.64 \\
\hline Cereals & 0.50 & 0.15 & 0.77 & 0.49 & 0.11 & 0.69 \\
\hline Pizza, pies, pancakes & 0.66 & $n / a^{d}$ & 0.22 & 0.77 & $\mathrm{n} / \mathrm{a}$ & 0.35 \\
\hline Meat, meat dishes & 0.34 & $<0$ & 0.47 & 0.36 & 0.06 & 0.65 \\
\hline Poultry, poultry dishes & 0.76 & $\mathrm{n} / \mathrm{a}$ & 0.33 & 0.78 & $\mathrm{n} / \mathrm{a}$ & 0.15 \\
\hline Spreads, oils & 0.34 & $<0$ & 0.56 & 0.29 & $<0$ & 0.38 \\
\hline Sweets, chocolate & 0.33 & 0.00 & 0.43 & 0.41 & 0.12 & 0.79 \\
\hline Cakes, biscuits & 0.23 & $\mathrm{n} / \mathrm{a}$ & 0.48 & 0.51 & 0.05 & 0.61 \\
\hline Other sweet foods & 0.37 & 0.04 & 0.49 & 0.39 & 0.06 & 0.62 \\
\hline Sweetened drinks & 0.44 & 0.07 & 0.63 & 0.48 & 0.17 & 0.72 \\
\hline Chips, crisps & 0.67 & $\mathrm{n} / \mathrm{a}$ & 0.22 & 0.34 & $\mathrm{n} / \mathrm{a}$ & 0.69 \\
\hline \multicolumn{7}{|l|}{ Nutrients } \\
\hline Energy & 0.36 & 0.07 & 0.60 & 0.33 & 0.06 & 0.58 \\
\hline Proteine & 0.36 & 0.05 & 0.57 & 0.42 & 0.16 & 0.67 \\
\hline Fate & 0.37 & 0.06 & 0.54 & 0.35 & 0.04 & 0.54 \\
\hline Saturated fate & 0.38 & 0.09 & 0.69 & 0.36 & 0.07 & 0.62 \\
\hline Carbohydrates ${ }^{\mathrm{e}}$ & 0.36 & 0.06 & 0.54 & 0.35 & 0.03 & 0.58 \\
\hline Sucrose $e^{e}$ & 0.39 & 0.11 & 0.57 & 0.38 & 0.07 & 0.71 \\
\hline Fibre & 0.36 & 0.09 & 0.65 & 0.48 & 0.26 & 0.94 \\
\hline Vitamin C & 0.38 & 0.04 & 0.42 & 0.42 & 0.19 & 0.76 \\
\hline Folic acid & 0.35 & 0.02 & 0.60 & 0.37 & 0.09 & 0.71 \\
\hline Iron & 0.35 & 0.04 & 0.48 & 0.34 & 0.04 & 0.58 \\
\hline Calcium & 0.43 & 0.18 & 0.75 & 0.39 & 0.06 & 0.62 \\
\hline Energy density & 0.35 & 0.06 & 0.65 & 0.40 & 0.16 & 0.58 \\
\hline
\end{tabular}

a Proportion remaining in the same tertile six years later

b Cohen's $\kappa$, Cohen's kappa (weighted)

c Predictive value for remaining in the highest tertile

dN/a: not applicable because three groups not available at both time points

e As a percentage of total energy

what parents and schools provide, adolescents to a lesser degree as both autonomy and the influence of peers increases, while young adults are usually independent and may have moved away from family and where they grew up. If dietary behaviour really does track, it is not clear whether this is due to the stability of food preferences, or to a lasting effect of, for example, parental influences. This is something that deserves further study.

\section{Evidence from other studies}

The current evidence for tracking behaviour in children and adolescents comes from studies varying in design, subject age and methods used. Studies have ranged over periods of one year to several decades, with longer studies usually including more data points. Some have focused on specific food groups (e.g. soft drinks $[25,26]$, or fruits and vegetables $[27,28])$, some on single nutrients [29], while others have examined overall dietary patterns [30,31]. Several of these studies have, like ours, been part of a larger cardiovascular disease study (e.g. the Bogalusa Heart Study [32], the Young Hearts Project [33], The Cardiovascular Risk in Young Finns Study [31], the CARDIA study [34]). The majority of published studies are from Europe or the USA, but one (English language) study from China [35] was identified via PubMed.

In the study most similar to ours in terms of subject age and tracking method used, Gallagher and colleagues found "substantial drift of subjects between low, medium and high classes of intakes", or slight and fair tracking of macronutrient and micronutrients over 12/13 years, from adolescence to young adulthood [36]. Like us, they used 
Cohen's weighted $\kappa$, but used the lowest $25^{\text {th }}$, the middle $50^{\text {th }}$ and the upper $25^{\text {th }}$ percentiles as their group cut-offs. Using energy adjusted nutrients, $\kappa$ values remained lower than 0.25. The Amsterdam Growth and Longitudinal Study has examined many aspects of tracking from ages 13 to 32, approximately. They used general estimating equations as they have many data points and have reported moderate tracking of energy in relation to body mass [37], low to moderate tracking for macro- and micronutrients [38] and fruit and vegetables [27]. In a comparable age group and time period, Lake et al have studied five food groups, based on the English national food model and found significant ranking correlations for three of them [39]. Over a similar length of time as our study (six years), but in much younger children (ages 3 and 4 at baseline), the Framingham Children's study found evidence of tracking, particularly for carbohydrate and fat [40]. Our results are in line with those of these studies, although the diversity makes it hard to compare directly.

\section{Usefulness of tracking coefficients}

Being able to predict future intakes from current intakes is of interest, both for nutritionists concerned about whether certain habits, for example, high sweetened drink consumption in adolescence, will remain high later on in life, or for those who want to know if high intakes achieved at a particular life-stage will have a lasting effect. We calculated a predictive value for remaining in the highest tertile of intake to help to answer questions such as: "what is the likelihood of someone with a high intake of vegetables at time I having a high intake at time II" ? Low fruit and vegetable intakes are a target of public health campaigns in many countries, including Sweden, and the results of this study would suggest that high vegetable intakes in childhood do not predict high intakes in adolescence, whereas high fruit intakes are more likely to remain high. High intakes of vegetables in adolescence on the other hand are more likely to remain high in young adulthood. However, only one food group, in the young age group, had a positive value for predicting membership of the highest tertile at follow-up (the milk, fil, yoghurt group).

The tracking of dietary intakes is important to study as it has implications for public health planning and epidemiology. From our results, it is not possible for us to conclude that the diet appears more stable from childhood to adolescence than from adolescence to young adulthood, or vice versa; both age groups showed comparable tracking values. While, statistically, we did see evidence of dietary tracking, it is also clear that many subjects do not remain in the same tertile, and so their behaviour, in both childhood and adolescence, appears potentially modifiable. This is potentially encouraging for health promoters and intervention planners. For epidemiologists, based on our results, in these age groups it would appear necessary to use a different dietary record method or more frequent data collections to be confident of classifying the intakes of these children and adolescents correctly.

\section{Limitations and strengths of the study}

Although this study presents data on two groups of 15year-olds, one from 1999 and one from 2004, attempts to examine temporal changes in intakes should be avoided. Given the participation and dropout bias it would be inappropriate to make assumptions about changes in the behaviour of 15-year-olds over time, based on this data. To detect temporal effects a more representative sample would be required. For this reason, certain differences in food and nutrient intakes between the two groups (which can be detected on examination of Tables 2 and 3) have not been highlighted or discussed.

Issues specific to the longitudinal study of diet are changes in food availability, food composition and promotion [41]. This could account for some of the changes, such as the large increase in poultry and poultry dishes consumption in the six years, which are promoted as healthier alternatives to red meat. The mis-reporting of dietary intake is a significant challenge to the quality of any dietary study. The simplest way to check for the presence of mis-reporting is to compare reported energy intakes to the estimated energy requirements, assuming weight stability of the subject. The method developed by Goldberg and colleagues [14], and elaborated on by Black [16], establishes cut-offs around this expected energy value, taking into account variability in dietary intake, variability in energy expenditure, and length of dietary record. The proportion of subjects who reported "inadequate" energy intakes in our sample was in line with other studies, but wide ranges (from 10 to 50\%) have been reported [42]. Unfortunately, the Goldberg method is not particularly sensitive at the individual level, especially when only one day of dietary data is available. We decided not to exclude inadequate reporters but rather to consider the effect that excluding them may have had on the results. This has been recommended as a minimum standard [43]. We found that excluding them had no substantial effect on the overall picture of tracking. All longitudinal studies are prone to the loss of subjects to follow-up. We have considered the potential influence this dropout might have on our study with a separate dropout analysis. The participation and dropout rates affect how the results of this study could be generalised to the general population. This is certainly the case when it comes to the median intakes, for example. However, we are not aware of any obvious theoretical reason to suspect that the tracking we observed would necessarily be any different in a more diverse population. In addition, data is presented at group level where 
possible, which is more appropriate for dietary data of this type [44]. The time period between data collections is quite long, and the availability of a third data point could have improved the study. Again, the longer time period would be expected to decrease the likelihood of detecting tracking. The 24-h recall interviewers were not the same in both years, but the training procedure and the trainers were. An updated nutritional database could account for some of the differences in nutrients seen, but this has no effect on intakes of food groups or ranking. Otherwise, the dietary data was processed and handled in the same way at both time points. Another strength of this study is that we have considered the effect of energy mis-reporting on our results. That energy mis-reporting is a huge issue for nutritional epidemiology is gaining recognition, but many studies still fail to address this clearly, and others fail to mention it at all.

\section{Conclusions}

Evidence for slight tracking was observed for most food groups and nutrients, indicating some modest stability of diet at individual level. This was despite the long time period between data collections, and the method of data collection used. However, many subjects do not maintain their ranking, implying that the diets of both children and adolescents are potentially modifiable. This topic warrants further study because of the relevance it has for the development of public health nutrition strategies in these age groups and for the design of future nutritional epidemiological studies.

\section{Competing interests}

The authors declare that they have no competing interests.

\section{Authors' contributions}

EP performed the analysis and drafted the manuscript. JW helped to plan the analysis and draft the manuscript. JK helped to draft the manuscript. MS was responsible for the study, oversaw data collection and helped to draft the manuscript. All authors read and approved the final manuscript.

\section{Acknowledgements}

The authors acknowledge the participants and their schools and families, as well as colleagues who performed the field work. This study was supported financially by Stockholm County Council.

\section{References}

I. Ovesen L: Adolescence: a critical period for long-term tracking of risk for coronary heart disease? Ann Nutr Metab 2006, 50(4):317-24.

2. Singh AS, Mulder C, Twisk JW, van Mechelen W, Chinapaw MJ: Tracking of childhood overweight into adulthood: a systematic review of the literature. Obes $\operatorname{Rev} 2008,9(5): 474-88$.

3. Birch LL, Fisher JO: Development of eating behaviors among children and adolescents. Pediatrics 1998, 101 (3 Pt 2):539-49.

4. Ashcroft J, Semmler C, Carnell S, van Jaarsveld CH, Wardle J: Continuity and stability of eating behaviour traits in children. Eur J Clin Nutr 2008, 62(8):985-90.
5. Story M, Neumark-Sztainer D, French S: Individual and environmental influences on adolescent eating behaviors. J Am Diet Assoc 2002, I 02(3 Suppl):S40-5I.

6. Lake AA, Rugg-Gunn AJ, Hyland RM, Wood CE, Mathers JC, Adamson AJ: Longitudinal dietary change from adolescence to adulthood: perceptions, attributions and evidence. Appetite 2004, 42(3):255-63.

7. Baranowski T, Mendlein J, Resnicow K, Frank E, Webber Cullen K, Baranowski J: Physical Activity and Nutrition in Children and Youth: An Overview of Obesity Prevention. Prev Med 2000, $3 I(2): S I-S I O$

8. Twisk JWR: Applied Longitudinal Data Analysis for Epidemiology. Cambridge: Cambridge University Press; 2003.

9. Northstone K, Emmett PM: Are dietary patterns stable throughout early and mid-childhood? A birth cohort study. BrJ Nutr 2008, 100(5):1069-76.

10. Riddoch CJ, Edwards D, Page AS, Froberg K, Anderssen SA, Wedderkopp N, Brage S, Cooper AR, Sardinha LB, Harro M, KlassonHeggebø L, van Mechelen W, Boreham C, Ekelund U, Andersen LB, the EYHS team: The European Youth Heart Study - Cardiovascular disease risk factors in children: Rationale, aims, study design and validation of methods. J Phys Act Health 2005, 2:115-129.

1I. Hurtig-Wennlöf A, Yngve A, Sjöström M: Sampling procedure, participation rates and representativeness in the Swedish part of the European Youth Heart Study (EYHS). Public Health Nutr 2003, 6(3):29I-9.

12. Grjibovski AM, Bergman P, Hagströmer M, Hurtig-Wennlöf A, Meusel D, Ortega FB, Patterson E, Poortvliet E, Rizzo N, Ruiz JR, Wärnberg J, Sjöström M: A dropout analysis of the second phase of the Swedish part of the European Youth Heart Study. J Public Health (Springer) 2006, I 4:26I-268.

13. Patterson E, Wärnberg J, Poortvliet E, Kearney J, Sjöström M: Dietary energy density as a marker of dietary quality in Swedish children and adolescents: the European Youth Heart Study. Eur J Clin Nutr in press.

14. Goldberg GR, Black AE, Jebb SA, Cole TJ, Murgatroyd PR, Coward WA, Prentice AM: Critical evaluation of energy intake data using fundamental principles of energy physiology: I. Derivation of cut-off limits to identify under-recording. Eur J Clin Nutr 199|, 45(I 2):569-81.

15. Black AE: Critical evaluation of energy intake using the Goldberg cut-off for energy intake:basal metabolic rate. A practical guide to its calculation, use and limitations. Int J Obes Relat Metab Disord 2000, 24(9): I I 19-30.

16. Black $A E$ : The sensitivity and specificity of the Goldberg cutoff for El:BMR for identifying diet reports of poor validity. Eur J Clin Nutr 2000, 54(5):395-404.

17. Schofield WN: Predicting basal metabolic rate, new standards and review of previous work. Human Nutrition: Clinical Nutrition 1985, 39C:5-4I.

18. Cole TJ, Bellizzi MC, Flegal KM, Dietz WH: Establishing a standard definition for child overweight and obesity worldwide: international survey. BMJ 2000, 320(7244):1240-3.

19. World Health Organisation: Obesity: preventing and managing the global epidemic. Report of a WHO consultation. In Tech. rep World Health Organisation, Geneva; 2000.

20. Cohen J: Weighted kappa: nominal scale agreement with provision for scaled disagreement or partial credit. Psychological Bulletin 1968, 70(4):213-220.

21. Landis JR, Koch GG: The measurement of observer agreement for categorical data. Biometrics 1977, 33:159-174.

22. Weighted kappa syntax for SPSS [http://support.spss.com/stu dent/Troubleshooting/sturessearchdetail.asp?!ID=24999]

23. Twisk JW: The problem of evaluating the magnitude of tracking coefficients. Eur J Epidemiol 2003, I 8(I I): I025-6.

24. Horst K van der, Oenema A, Ferreira I, Wendel-Vos W, Giskes K, Brug J: Potential determinants of selected dietary behaviours in youth. In Environmental determinants and interventions for physical activity, nutrition and smoking: A review Edited by: Brug J, van Lenthe F. Zoetermeer: Speed-Print; 2005:240-80.

25. Nelson MC, Neumark-Sztainer D, Hannan PJ, Story M: Five-year longitudinal and secular shifts in adolescent beverage intake: findings from project EAT (Eating Among Teens)-II. J Am Diet Assoc 2009, 109(2):308-12. 
26. Kvaavik $\mathrm{E}$, Andersen LF, Klepp $\mathrm{KI}$ : The stability of soft drinks intake from adolescence to adult age and the association between long-term consumption of soft drinks and lifestyle factors and body weight. Public Health Nutr 2005, 8(2): 149-57.

27. te Velde SJ, Twisk JW, Brug J: Tracking of fruit and vegetable consumption from adolescence into adulthood and its longitudinal association with overweight. $\mathrm{Br} /$ Nutr 2007, 98(2):43I-8.

28. Resnicow K, Smith M, Baranowski T, Baranowski J, Vaughan R, Davis M: 2-year tracking of children's fruit and vegetable intake. J Am Diet Assoc 1998, 98(7):785-9.

29. Welten DC, Kemper HC, Post GB, Van Staveren WA, Twisk JW: Longitudinal development and tracking of calcium and dairy intake from teenager to adult. Eur J Clin Nutr 1997, 5 I (9):6I2-8.

30. Borland SE, Robinson SM, Crozier SR, Inskip HM: Stability of dietary patterns in young women over a 2-year period. Eur J Clin Nutr 2008, 62: I 19-26. [SWS Study Group].

31. Mikkilä V, Räsänen L, Raitakari OT, Pietinen P, Viikari J: Consistent dietary patterns identified from childhood to adulthood: the cardiovascular risk in Young Finns Study. Br J Nutr 2005, 93(6):923-3I.

32. Nicklas TA, Webber LS, Berenson GS: Studies of consistency of dietary intake during the first four years of life in a prospective analysis: Bogalusa Heart Study. J Am Col I Nutr 199I, I0(3):234-4I.

33. Robson PJ, Gallagher AM, Livingstone MB, Cran GW, Strain JJ, Savage JM, Boreham CA: Tracking of nutrient intakes in adolescence: the experiences of the Young Hearts Project, Northern Ireland. Br J Nutr 2000, 84(4):54|-8.

34. Dunn JE, Liu K, Greenland P, Hilner JE, Jacobs JDR: Seven-year tracking of dietary factors in young adults: the CARDIA study. Am J Prev Med 2000, 18:38-45.

35. Wang $Y$, Bentley ME, Zhai F, Popkin BM: Tracking of dietary intake patterns of Chinese from childhood to adolescence over a six-year follow-up period. J Nutr 2002, I32(3):430-8.

36. Gallagher AM, Robson PJ, Livingstone MB, Cran GW, Strain JJ, Murray LJ, Savage JM, Boreham CA: Tracking of energy and nutrient intakes from adolescence to young adulthood: the experiences of the Young Hearts Project, Northern Ireland. Public Health Nutr 2006, 9(8): 1027-34.

37. Kemper HC, Post GB, Twisk JW, van Mechelen W: Lifestyle and obesity in adolescence and young adulthood: results from the Amsterdam Growth And Health Longitudinal Study (AGAHLS). Int J Obes Relat Metab Disord 1999, 23(Suppl 3):S34-40.

38. Bertheke Post G, de Vente W, Kemper HC, Twisk JW: Longitudinal trends in and tracking of energy and nutrient intake over 20 years in a Dutch cohort of men and women between 13 and 33 years of age: The Amsterdam growth and health longitudinal study. Br J Nutr 200I, 85(3):375-85.

39. Lake AA, Mathers JC, Rugg-Gunn AJ, Adamson AJ: Longitudinal change in food habits between adolescence ( $I 1-12$ years) and adulthood (32-33 years): the ASH30 Study. J Public Health (Oxf) 2006, 28: $10-16$.

40. Singer MR, Moore LL, Garrahie EJ, Ellison RC: The tracking of nutrient intake in young children: the Framingham Children's Study. Am J Public Health 1995, 85( I 2): 1673-7.

41. Sempos CT, Flegal KM, Johnson CL, Loria CM, Woteki CE, Briefel RR: Issues in the long-term evaluation of diet in longitudinal studies. J Nutr 1993, I23(2 Suppl):406-12.

42. Livingstone MBE, Robson PJ, Black AE, Coward WA, Wallace JMW McKinley MC, Strain JJ, McKenna PG: An evaluation of the sensitivity and specificity of energy expenditure measured by heart rate and the Goldberg cut-off for energy intake: basal metabolic rate for identifying mis-reporting of energy intake by adults and children: a retrospective analysis. Eur $\int$ Clin Nutr 2003, 57(3):455-463.

43. Goldberg GR, Black AE: Assessment of the validity of reported energy intakes - review and recent developments. Scandinavian Journal of Nutrition/Näringsforskning 1998, 42:6-9.

44. Beaton GH, Milner J, Corey P, McGuire V, Cousins M, Stewart E, de Ramos M, Hewitt D, Grambsch PV, Kassim N, Little JA: Sources of variance in 24-hour dietary recall data: implications for nutrition study design and interpretation. Am J Clin Nutr 1979, 32(I 2):2546-2559.
Publish with Biomed Central and every scientist can read your work free of charge

"BioMed Central will be the most significant development for disseminating the results of biomedical research in our lifetime. "

Sir Paul Nurse, Cancer Research UK

Your research papers will be:

- available free of charge to the entire biomedical community

- peer reviewed and published immediately upon acceptance

- cited in PubMed and archived on PubMed Central

- yours - you keep the copyright 